\title{
LUARAN FUNGSIONAL DARI PEMBEDAHAN RUPTUR LIGAMEN MEDIAL PATELLOFEMORAL DI RUMAH SAKIT HASAN SADIKIN BANDUNG
}

\author{
Perdana M.F.N., Utoyo G.A., Prasetia HNR., Fadli S. \\ Departmen Orthopaedi and Traumatologi
}

Fakultas Kedokteran Universitas Padjadjaran/RSUP DR. Hasan Sadikin Bandung

\begin{abstract}
Abstrak
Pendahuluan: Dislokasi patella dan cedera yang berhubungan dengan medial patellofemoral ligament (MPFL) merupakan cedera lutut yang paling umum pada masa remaja yang memberikan kontribusi 53 hingga $60 \%$ dari gaya tarik medial terhadap pergeseran ke arah lateral. Tujuan dari penelitian ini adalah untuk menggambarkan luaran fungsional setelah operasi pembedahan ruptur ligamen medial patellofemoral dilaksanakan pada center kami.

Metodologi: Penelitian analitik observasional pada 'pasien cedera MPFL antara Januari 2015 dan Juli 2019 dengan jumlah 31 pasien. Pencarian database indeks medis/bedah di Rumah Sakit Hasan Sadikin Bandung dilakukan dengan menggunakan kata kunci Cedera Ligamentum Patellofemoral Medial dan ruptur Ligamentum Patellofemoral Medial dengan hasil data berupa catatan klinis dan operatif, serta studi pencitraan. Hasil klinis dievaluasi menggunakan Skor Kujala untuk menilai rasa sakit, kualitas hidup, dan kekambuhan.

Hasil: 31 pasien memenuhi kriteria inklusi dan menjalani operasi selama 2 tahun. Menurut jenis kelamin terdapat 11 pasien pria $(35,48 \%)$ dan 20 wanita pasien $(64,52 \%)$. Usia rata-rata adalah 26,87 tahun (kisaran $15-$ 42 tahun). Mekanisme cedera pada 23 pasien adalah cedera olahraga $(74,2 \%)$ dan 8 pasien cedera non-olahraga. Terdapat 25 pasien $(80,64 \%$ ) yang menjalani operasi MPFL dengan retinacular lateral release, dan 6 pasien $(19,36 \%)$ menjalani operasi MPFL tanpa lateral retinacular release. 22 pasien $(70,96 \%)$ menjalani rekonstruksi MPLF dengan endo-button dan graft, dan 9 pasien (29,04\%) menjalani perbaikan MPFL dengan jahitan primer. Terdapat peningkatan median skor Kujala sebelum dan setelah operasi (setelah 1 tahun), dari 63,90 (kisaran 4575) menjadi 88,19 (kisaran 80-100) dan dianalisis dengan pair t-test dengan hasil signifikan secara statistik (p $<0,05)$.
\end{abstract}

Kesimpulan: Tatalaksana dislokasi patella menggunakan rekonstruksi MPFL menunjukkan luaran klinis yang lebih baik yaitu sangat mengurangi rasa sakit, tingkat kekambuhan, dan membantu meningkatkan kualitas hidup.

Kata Kunci: ligament rupture, medial patellofemoral ligament, kujala score

\section{Pendahuluan}

\section{Ketidakstabilan patellofemoral}

dapat mengenai atlet maupun non-atlet, sehingga menimbulkan rasa sakit, kecacatan, dan seringkali membutuhkan pembedahan. Dalam keadaan tidak terluka, stabilitas patellofemoral disokong oleh struktur tulang dan jaringan lunak. $^{1-3}$ Ketika terjadi gerakan fleksi dari 20 hingga 30 derajat, sisi lateral patela menghubungi aspek medial kondilus femoralis lateral, yang berfungsi sebagai penopang terhadap gerakan translasi lateral lebih lanjut. Kondilus femoralis yang mendatar (displastik) adalah variasi tulang yang umum dalam anatomi yang dapat menyebabkan ketidakstabilan patellofemoral. ${ }^{4}$ Dalam beberapa tahun terakhir, banyak peneliti telah memfokuskan pada ligamentum 
patellofemoral medial (MPFL) dalam kasus dislokasi patella. Secara anatomis, MPFL adalah serabut tipis dari jaringan retinacular yang secara transversal menghubungkan dari kondilus medial ke aspek medial patela, menempel pada permukaan bawah dari vastus medialis oblique (VMO) proksimal pada insersi patela.

Peran penting dari ligamentum patellofemoral medial (MPFL) bersama ligamentum patellomeniscal medial, ligamentum patellotibial medial, retinakulum medial, dan retinakulum lateral adalah untuk menjaga agar patella tidak subluksasi ke arah lateral atau biasa kita sebut dislokasi. Ketika struktur ini melemah,maka kemungkinan translasi (pergeseran) dapat terjadi dan akhirnya dislokasi patella dapat terjadi. Dari struktur-struktur ini, MPFL sejauh ini merupakan struktur yang paling penting dan gangguannya sering disebut sebagai lesi esensial dari dislokasi lateral dari patella. ${ }^{5-6}$ Studi pada diseksi kadaver telah menunjukkan bahwa MPFL memberikan $50 \%$ hingga $60 \%$ dari penguatan jaringan untuk menahan translasi ke arah lateral, ${ }^{7}$ sedangkan ligamentum patellomeniscal medial berkontribusi $24 \% .{ }^{8}$ MPFL adalah lapisan ke 2 dari aspek medial lutut, dalam dan agak distal ke arah vastus medialis. Perlekatan ke arah femoral biasanya pada aspek posterior epikondilus medial, proksimal ke ligamen kolateral medial dan $1 \mathrm{~cm}$ distal ke tuberkulum adduktor. Perlekatan pada patela menempati aspek medial superior dari patela, biasanya $1 \mathrm{~cm}$ ke kutub superior. Perlekatan tambahan sering ditemukan pada permukaan bawah dari vastus medialis. ${ }^{9}$ Ligamen itu sendiri rata-rata panjangnya $58,8 \mathrm{~mm}$, lebar $12 \mathrm{~mm}$, dan tebal $0,44 \mathrm{~mm} .{ }^{10}$

Saat ini, pola cedera MPFL yang umum digunakan telah diidentifikasi dan dikategorikan ke dalam empat jenis berdasarkan temuan MRI: cedera pada insersi patela, midsubstance, origo dari femoral, dan cedera kombinasi. ${ }^{9,10}$ Namun, sulit untuk membedakan cedera midsubstance dari pola cedera patela atau femoralis ketika cedera terletak pada insersi patella midsubstance atau zona junctional insersi midsubstance-femoral. Selain itu, cedera midsubstance yang sama dapat menyebabkan hasil klinis yang berbeda, dengan atau tanpa adanya ikatan VMO. Pada awal 1915, teknik bedah telah dipelajari untuk mengatasi ketidakstabilan yang disebabkan oleh kondilus femoralis lateral displastik. ${ }^{4,5}$ Prosedur ini termasuk osteotomi, trochleoplasty (elevasi kartilago artikular dan pendalaman grove trochlear $^{8,9}$ ), dan rekonstruksi jaringan ikat semata. ${ }^{10}$ Sejumlah besar opsi rekonstruksi juga telah dideskripsikan untuk 
mengkompensasi hilangnya MPFL. Hal ini berkisar dari prosedur distal realignment, ${ }^{4,5}$ lateral release, ${ }^{6,7}$ dan apakah perbaikan, imbrication, atau rekonstruksi struktur medial. ${ }^{8,9}$ Rekonstruksi MPFL dengan semitendinosus, 9,10 gracilis, tendon quadriceps, ${ }^{9-10}$ dan bahkan graft sintetis ${ }^{8,9}$ sudah dipelajari. ${ }^{10}$ Tidak ada data yang jelas yang disajikan menunjukkan keunggulan dari satu teknik bedah atas yang lain.

Terdapat beberapa Teknik operasi yang dapat dilakukan. Pertama, Lateral Retinacular Lengthening. Yaitu berupa prosedur lateral retinacular lengthening yang dilakukan secara arthroscopic jika uji tilt test positive pada pemeriksaan pra operasi. Probe rediofrekuensi yang melengkung dimasukkan ke portal anterolateral. Secara visualisasi langsung, dibuat pemotongan partial-thicknes pada retinaculum lateral, secara analogi sama dengan teknik pemanjangan ligamen kolateral medial "pie-crusting" teknik, di beberapa lokasi di sepanjang retinaculum lateral. Pompa tekanan cairan arthroscopic digunakan untuk memberi tekanan pada jaringan sebesar $50 \mathrm{~mm} \mathrm{H} 2 \mathrm{O}$, yang menyebabkan pemanjangan retinakulum secara relatif. Uji "tilt test" patellar kembali dilakukan. Jika tetap positif, "pie crusting" retinacular lateral diulang sampai "tilt test" negatif. Kedua, MPFL Repair.
Dijelaskan bahwa bergantung pada lokasi robekannya, sayatan kulit kecil dibuat dan MPFL diidentifikasi secara pembedahan antara lapisan 2 dan 3,5. Allis Clamp ditempatkan pada tepi yang sobek. Kemudian, jangkar jahitan ditempatkan di insersi anatomi (patella vs femur) setelah sebelumnya disiapkan dengan bur. Lutut kemudian ditekuk hingga $30^{\circ}$, pembedahan menempatkan patela di trochlea, dan perbaikan dilakukan setelah menegangkan MPFL. Ketiga, MPFL Reconstruction. Dijelaskan bahwa sayatan kecil dibuat pada daerah proksimal-medial patella, dan sisi medial patela terbuka. Pendarahan tulang ditangani dengan menggunakan bur, memastikan korteks tidak sepenuhnya tertebus. Jangkar jahitan kemudian ditempatkan pada posisi jam 12:30, 1:30, dan 2:30 pada sisi medial patela (9:30, 10:30, dan 11:30 untuk patela kiri). Bagian tengah semitendinosus allograft kemudian dilekatkan pada jangkar menggunakan jahitan matras horizontal. Interval antara lapisan 2 dan 3 dilebarkan menggunakan curved clamp, dan cangkokan dilewatkan melalui lapisan ini ke sayatan femoralis. Sayatan berbasis femoralis dibuat di atas pemasangan femoral MPFL. Fluoroskopi tidak digunakan untuk menemukan insersi anatomi. Setelah melindungi cabangcabang saraf saphenous, fasia diinsisi atas insersi anatomi. Ujung cangkok diambil dan di jahit dengan jahitan No. 2. Pin 
jarum dilewatkan dari insersi tulang (hanya distal dan posterior ke adductor tubercle) ke korteks lateral, mengarah ke anterior dan proksimal. Alat "Reamer" 8-mm digunakan untuk membuat "bony socket" sekitar $40 \mathrm{~mm}$. Ujung cangkokan dilewatkan ke dalam terowongan melalui pin beath. Dokter bedah memegang patela di tengah-tengah trochlea dengan lutut fleksi $30^{\circ}$. Graft diikat dan diamankan dengan interference screw.

\section{Bahan dan Metode}

Desain pada penelitian ini adalah analitik observasional pada 'pasien cedera MPFL antara Januari 2015 dan Juli 2019. Pencarian database indeks medis / bedah di Rumah Sakit Hasan Sadikin Bandung dilakukan dengan menggunakan kata kunci Cedera Ligamentum Patellofemoral Medial dan ruptur Ligamentum Patellofemoral Medial. Sebanyak 31 pasien terindentifikasi dalam kerangka waktu ini. Catatan yang ada termasuk catatan klinis dan operatif, serta studi pencitraan (radiografi, CT Scan, dan pencitraan MRI). Data yang diambil termasuk jenis kelamin, usia, pekerjaan, mekanisme cedera, dan teknik detail operasi. Hasil klinis kemudian dievaluasi dengan menggunakan Skor Kujala untuk menilai rasa sakit, kualitas hidup, dan kekambuhan.
Skor Kujala adalah kuesioner yang paling sering digunakan untuk gangguan patellofemoral seperti nyeri, ketidakstabilan atau osteoartritis. Skor Kujala adalah instrumen skrining 13-item yang dirancang untuk menilai nyeri patellofemoral pada remaja dan dewasa muda, dengan format respons ordinal variabel. Adapun 13 item yang menjadi variable adalah Limp, Support, Walking, Stairs, Squatting, Running, Jumping, Prolonged sitting with knee flexed, Pain, Swelling, Abnormal painful kneecap movements, Atrophy of thigh, dan Flexion deficiency. Misalnya, skor 'Limp' akan dinilai sebagai berikut: tidak ada (5), sedikit / periodik (3), konstan (0). Total skor berkisar dari 0 hingga 100. Myer et al. telah menawarkan formulir pendek 6-item berdasarkan item-item yang disederhanakan dan dikodekan ulang. Dengan demikian, skor 'Limp' dikodekan ulang sebagai: tidak ada (0), sedikit / periodik / konstan (1).

\section{Hasil}

Terdapat 31 pasien yang memenuhi kriteria inklusi dan menjalani operasi selama kurun waktu 2 tahun. Menurut jenis kelamin terdapat 11 pasien pria $(35,48 \%)$ dan 20 wanita pasien $(64,52 \%)$. Usia ratarata adalah 26,87 tahun (kisaran 15-42 tahun). Berdasarkan gambar 1, mekanisme cedera pada 23 pasien adalah cedera 
olahraga $(74,2 \%)$ dan 8 pasien cedera nonolahraga. Berdasarkan gambar 2 pada jenis operasi, terdapat 22 pasien $(70,96 \%)$ menjalani rekonstruksi MPFL dengan endo-button dan graft, dan 9 pasien $(29,04 \%)$ menjalani perbaikan MPFL dengan jahitan primer. Berdasarkan gambar 3, terdapat 25 pasien $(80,64 \%)$ yang menjalani operasi MPFL dengan retinacular lateral release, dan 6 pasien $(19,36 \%)$ menjalani operasi MPFL tanpa lateral retinacular release.

Terdapat peningkatan median skor Kujala sebelum operasi dan setelah operasi (setelah 1 tahun), dari 63,90 (kisaran 4575) menjadi 88,19 (kisaran 80-100) dan dianalisis dengan pair t-test dengan hasil signifikan secara statistik ( $\mathrm{p}<0,05)$.

\section{Pembahasan}

Dalam penelitian ini usia rerata adalah 26,87 tahun, tidak ada perbedaan dengan penelitian sebelumnya yang menunjukkan usia rerata adalah 24 tahun. Ini menunjukkan bahwa rata-rata usia pada kasus rupture MPFL terjadi pada usia dewasa muda. Pasien ruptur MPFL dalam penelitian ini menemukan bahwa terdapat lebih banyak kasus pada pasien wanita daripada pasien pria. Temuan ini mirip dengan penelitian sebelumnya. Dalam sebuah penelitian terhadap 24 pasien dengan ruptur MPFL oleh Jason et al,
33,33\% (8 dari 24) yang di tangani dengan rekonstruksi MPFL dan 66,67\% (16 dari 24) dengan repair MPFL. Dalam penelitian ini, 70,96\% (22 dari 31) di operasi dengan rekonstruksi MPFL, dan 29,04\% (9 dari 31) menjalani operasi repair MPFL. Pada penelitian sebelumnya oleh Jason et al, 87,5\% (21 dari 24) dilakukan retinaculum lateral release, dan $12,5 \%$ (3 dari 24) dilakukan tanpa retinaculum lateral release. ${ }^{2}$ Dalam penelitian ini, 74,19\% (23 dari 31) menjalani operasi MPFL dengan retinaculum lateral release, dan 25,81\% (8 dari 31) menjalani operasi tanpa retinaculum lateral release. ${ }^{2}$

Skor Kujala digunakan untuk menilai luaran klinis dari operasi. ${ }^{3}$ Sebelum operasi, median skor Kujala adalah 63,90 (kisaran 45-75), dan setelah semua pasien menjalani operasi, skor median Kujala adalah 88,19 (kisaran 80 100) sebagian besar pasien tidak mengeluh tentang rasa sakit lagi. Perbedaan skor sebelum dan sesudah operasi diuji dengan pair t-test. Hasil uji statistik dalam penelitian ini diperoleh informasi bahwa nilai $\mathrm{P}$ pada skor variabel Kujala lebih kecil dari 0,05 (nilai $\mathrm{P}<0,05$ ) yang berarti bermakna secara statistik sehingga dapat dijelaskan bahwa terdapat perbedaan yang signifikan secara statistik antara skor Kujala sebelum dan sesudah operasi. ${ }^{3}$ 


\section{Kesimpulan}

\begin{tabular}{ccc}
\multicolumn{2}{c}{ Tatalaksana dislokasi patella } \\
menggunakan rekonstruksi & MPFL
\end{tabular} menunjukkan luaran klinis yang lebih baik. Tindakan ini sangat mengurangi rasa sakit, tingkat kekambuhan, dan membantu meningkatkan kualitas hidup.

\section{Referensi}

1. Kang H, Wang F, Chen C, et all. Nonsurgical treatment for acute patellar dislocation with special emphasis on the MPFL injury patterns. Verlag Springer 2012

2. Dragoo JL, Nguyen M, Gatewood CT, Taunton JD, Young S. Medial Patellofemoral Ligament Repair Versus Reconstruction for Recurrent Patellar Instability Two-Year : Results of an Algorithm-Based Approach. The Orthopaedic Journal of Sports Medicine. 2017.DOI:

\section{$10.1177 / 2325967116689465$}

3. Kujala UM, Jaakkola LH, Koskinen SK, Taimela S, Hurme M, Nelimarkka O. Scoring of patellofemoral disorders. The Journal of Athroscopic and Related Surgery. 1993

4. LeGrand AB, Greis PE, Dobbs RE, Burks RT. MPFL Reconstruction. Sports Med Arthrosc Rev. Lippincott Williams \& Wilkins. 2007
5. Panagiotopoulos E, Strzleczyk P, Herrmann M, et al. Cadaveric study on static medial patellar stabilizers: the dynamizing role of the vastus medialis obliquus on medial patellofemoral ligament. Knee. 2006;14:7-12

6. Balcarek P, Ammon J, Frosch S, Ferlemann KG, Lill H, Stürmer KM, Frosch KH Magnetic resonance imaging characteristics of the medial patellofemoral ligament lesion in acute lateral patellar dislocations considering trochlear dysplasia, patella alta, and tibial tuberosity-trochlear groove distance.2010. Arthroscopy 26:926-935

7. Balcarek P, Walde TA, Frosch S, Schu“ttrumpf JP, Wachowski MM, Stürmer KM, Frosch KH Patellar dislocations in children, adolescents and adults: a comparative MRI study of medial patellofemoral ligament injury patterns and trochlear groove anatomy.2011. Eur J Radiol 79:415420.

8. Weber-Spickschen TS, Spang J, Kohn L, Imhoff AB, Schottle PB.The relationship between trochlear dysplasia and medial patellofemoral ligament rupture location after patellar dislocation: an MRI evaluation.2011. Knee 18:185-188.

9. Noyes FR, Albright JC. Reconstruction of the medial 
patellofemoral ligament with vastus medialis obliquus-plasty for autologous quadriceps tendon. lateral patellar dislocation. Orthopade. Arthroscopy. 2006;22:904.e1-904.e 2006;35:94-101.

10. Krause F, Kolling C, Brantschen R, et al. Medium-term results after $\mathrm{m}$.

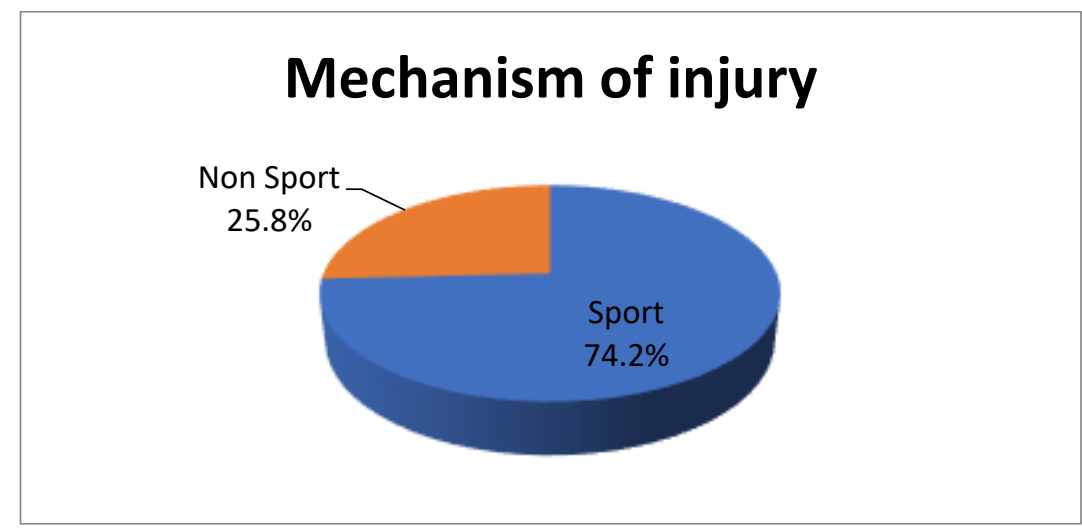

Gambar 1. Mechanism of injury

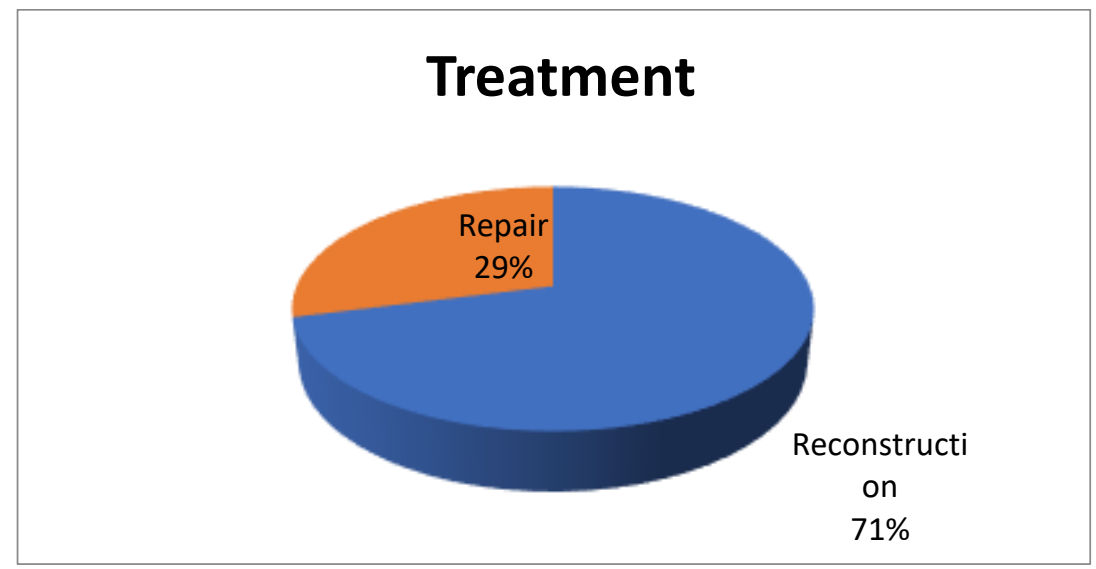

Gambar 2. Surgical Treatment 


\section{Lateral retinacular release}

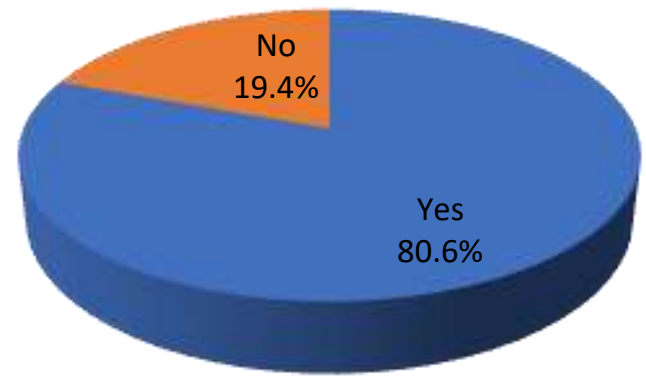

Gambar 3 . MPFL Surgery with Lateral retinacular release

Tabel 1. Gambaran Karakteristik Subjek Penelitian

\begin{tabular}{lc}
\hline Variabel & $\mathbf{N}=\mathbf{3 1}$ \\
\hline Usia & \\
Mean \pm Std & $26.87 \pm 6.878$ \\
Median & 26.00 \\
Range (Min-Max) & $15.00-42.00$ \\
Jenis Kelamin & \\
Pria & \\
Wanita & $11(35,48 \%)$ \\
Diagnosis & $20(64,52 \%)$ \\
MPFL rupture & \\
Tindakan & $31(100.0 \%)$ \\
Reconstruction & \\
Repair & \\
Lateral retinacular release & $22(71.0 \%)$ \\
Yes & $9(29.0 \%)$ \\
No & \\
Mechanism of Injury & $25(80.6 \%)$ \\
Sport & $6(19.4 \%)$ \\
Non Sport & \\
\hline Ketergan : & \\
\hline
\end{tabular}

Keterangan : Untuk data kategorik disajikan dengan jumlah/frekuensi dan persentase sedangkan data numerik disajikan dengan rerata, median, standar deviasi dan range. 
Tabel 2. Perbandingan antara Kujala Score sebelum dan setelah operasi

\begin{tabular}{lccc}
\hline \multirow{2}{*}{ Variabel } & \multicolumn{2}{c}{ Kelompok } & Nilai P \\
\cline { 2 - 3 } & $\begin{array}{c}\text { Before operation } \\
\mathbf{N = 3 1}\end{array}$ & $\begin{array}{c}\text { After operation } \\
\mathbf{N = 3 1}\end{array}$ & $\mathbf{0 . 0 0 0 1 * *}$ \\
Kujala score & & & \\
Mean \pm Std & $63.90 \pm 7.790$ & $88.19 \pm 5.700$ & 88.00 \\
Median & 65.00 & $80.00-100.00$ & \\
Range (Min-Max) & $45.00-75.00$ & & \\
\hline
\end{tabular}

Keterangan : Untuk data numerik nilai p diuji dengan uji T berpasangan apabila data berdsitribusi normal dengan alternatif uji Wilcoxon apabila data tidak berdistribusi normal..Nilai kemaknaan berdasarkan nilai $\mathrm{p}<0,05$ .Tanda* menunjukkan nilai $\mathrm{p}<0,05$ artinya signifkan atau bermakna secara statistik. 